\title{
INFLUÊNCIA DA SALINIDADE SOBRE O CRESCIMENTO, ABSORÇÃO E DISTRIBUIÇÃO DE SÓDIO, CLORO E MACRONUTRIENTES EM PLÂNTULAS DE MARACUJAZEIRO-AMARELO $\left({ }^{1}\right)$
}

\author{
JAILSON LOPES CRUZ $\left({ }^{2}\right)$; CLAUDINÉIA REGINA PELACANI $\left({ }^{3}\right)$; EUGÊNIO FERREIRA COELHO $\left({ }^{2}\right)$; \\ RANULFO CORREA CALDAS $\left({ }^{2}\right)$; ADRIANA QUEIROZ DE ALMEIDA $\left({ }^{4}\right)$; JUREMA ROSA DE QUEIROZ $\left({ }^{5}\right)$
}

\begin{abstract}
RESUMO
A presença de sódio $(\mathrm{Na})$ e de cloro $(\mathrm{Cl})$ no substrato tem ocasionado redução no crescimento dos vegetais, em virtude desses íons causarem, entre outros efeitos negativos, mudanças na capacidade das plantas em absorver, transportar e utilizar alguns dos nutrientes. Assim, o objetivo do presente trabalho foi o de avaliar a influência da salinidade sobre o crescimento e a absorção e distribuição do $\mathrm{Na}$ e $\mathrm{Cl}$ e dos macronutrientes em plântulas de Maracujazeiro-amarelo, durante 50 dias de crescimento sob condições salinas, em vasos com capacidade para 2,2 dm³. Foram utilizados três níveis de $\mathrm{NaCl}(0,50$ e $100 \mathrm{~m}$ mol $\mathrm{L}^{-1}$ ). Observou-se que a altura, o número de folhas, a área foliar e a massa seca de todas as partes da planta foram significativamente reduzidas pela salinidade. A concentração dos íons $\mathrm{Na}$ e $\mathrm{Cl}$ aumentaram com o acréscimo da salinidade no meio de cultivo, porém, foram parcialmente retidos na raiz, no caso do $\mathrm{Cl}$, e nas folhas mais velhas, no caso do $\mathrm{Na}$. As concentrações de nitrogênio (N), fósforo (P) e cálcio (Ca) não foram afetadas pela salinidade. As concentrações de potássio (K), ao contrário, decresceram em todas as partes da planta, enquanto as do enxofre $(S)$ foi reduzida apenas nas raízes. Dada a pequena redução nas características de crescimento conclui-se que o Maracujazeiro-amarelo é uma espécie moderadamente tolerante ao estresse salino.
\end{abstract}

Palavras-chave: estresse salino, $\mathrm{NaCl}$, tolerância, crescimento, massa seca.

\section{Abstract \\ INFLUENCE OF NaCl SALINITY ON UPTAKE AND DISTRIBUTION OF SODIUM, CHLORIDE AND MACRONUTRIENTS IN YELLOW PASSION FRUIT SEEDLINGS}

The presence of sodium $(\mathrm{Na})$ and chloride $(\mathrm{Cl})$ in growth medium have leaded to crop growth due to negative effects of these ions such as changes in plant capacity of uptake, transport and use of essential nutrients. The objective of this work was to evaluate the influence of salinity on growth, uptake and transport of $\mathrm{Na}, \mathrm{Cl}$ and macronutrients in yellow passion fruit plants. Three levels of $\mathrm{NaCl}\left(0,50\right.$ and $\left.100 \mathrm{~m} \mathrm{~mol} \mathrm{~L}^{-1}\right)$ were tested. Experiment was finished after 50 days of growing in $2.2 \mathrm{dm}^{3}$ pots. It was noticed that height, leaf number, leaf area and dry mass of all parts of the plant were reduced by salinity. The concentration

$\left(^{1}\right)$ Recebido para publicação em 22 de maio de 2005 e aceito em 27 de abril de 2006.

( ${ }^{2}$ Embrapa Mandioca e Fruticultura Tropical, Caixa Postal 007, 44380-000 Cruz das Almas (BA). Autor correspondente. E-mail: jailson@cnpmf.embrapa.br.

$\left({ }^{3}\right)$ Departamento de Biologia Vegetal, Universidade Estadual de Feira de Santana, Rod. BR-116, 44031-460 Feira de Santana (BA).

(4) Discente da Escola de Agronomia da UFBA, 44380-000 Cruz das Almas (BA). Bolsista da FAPESB.

$\left({ }^{5}\right)$ Discente da Escola de Agronomia da UFBA, 44380-000 Cruz das Almas (BA). Bolsista do CNPq. 
of $\mathrm{Na}$ and $\mathrm{Cl}$ ions increased with the increasing of salinity. However, ions were retained partially in roots $(\mathrm{Cl})$ and in older leaves $(\mathrm{Na})$. Concentration of nitrogen $(\mathrm{N})$, phosphorous $(\mathrm{P})$ and calcium $(\mathrm{Ca})$ were not affected by salinity. Actually, concentration of potassium (K) was reduced in all parts of the plant while sulfur $(S)$ was reduced only in roots. Based upon the short reduction on growth characteristics, it was concluded that yellow passion fruit crop has a moderated tolerance to saline stress.

Key words: salinity stress, tolerance, growth, dry mass.

\section{INTRODUÇÃO}

O manejo inadequado da água de irrigação aliado ao uso intensivo de fertilizantes têm contribuído para o aumento de áreas agricultáveis com problemas de salinidade. Esse fato é particularmente importante nas regiões áridas e semiáridas, devido à escassez da precipitação pluvial e à alta demanda evaporativa, que dificultam a lixiviação dos sais localizados na camada arável do solo. Estimase que no Brasil existam, aproximadamente, nove milhões de hectares com problemas de salinidade, a maior parte dessa área localizada nos perímetros irrigados do Nordeste (CARNEIRO et al., 2002).

Diversos trabalhos têm evidenciado o efeito negativo dos íons que contribuem para a salinidade do solo (principalmente $\mathrm{Na}$ e $\mathrm{Cl}$ ) sobre processos fisiológicos importantes para o crescimento das plantas (YAHYA, 1998; BetHKE E DReW, 1992). Os efeitos desses íons estão relacionados ao efeito osmótico, que induz condição de estresse hídrico às plantas e ao efeito tóxico direto, principalmente sobre os sistemas enzimáticos e de membranas.

O limite de tolerância depende da concentração do sal em solução, do tempo de exposição, bem como do estádio de desenvolvimento das plantas (Ayers e Westcot, 1991). Apesar da existência de variabilidade genética para tolerância à salinidade (Shannon E Grieve, 1998), os mecanismos bioquímicos e fisiológicos que contribuem para essa tolerância ainda são pouco conhecidos (MANsour et al., 2003). Um dos mecanismos comumente citado para tolerância à salinidade tem sido a capacidade das plantas em acumular íons no vacúolo e, ou, solutos orgânicos de baixo peso molecular no citoplasma, em um processo denominado de ajustamento osmótico, que pode permitir a manutenção da absorção de água e da turgescência celular (Hopkins, 1999). Outro mecanismo de tolerância pode estar relacionado a diferenças na absorção, transferência e, ou, acumulação de íons $\mathrm{Na}$ e $\mathrm{Cl}$. Para LACERDA et al. (2001), por exemplo, em variedades de sorgo sensíveis à salinidade observam-se maiores taxas de absorção e transferência de $\mathrm{Na}$ e $\mathrm{Cl}$ para a parte aérea e maior acúmulo desses íons nas folhas fisiologicamente ativas.
Indiretamente, o menor crescimento das plantas, devido à salinidade, também tem sido atribuído à redução na absorção de alguns dos principais nutrientes, estando o Ca e o $\mathrm{K}$ entre os mais bem documentados (RENGEL, 1992; LACERDA, 2000). Trabalhando com plantas jovens de goiabeira, FERREIRA et al. (2001), por exemplo, verificaram redução na concentração de $\mathrm{K}$ nos tecidos da planta (raízes, caule e folhas), como conseqüência do estresse salino. Essa menor absorção de $\mathrm{K}$ tem sido atribuída à maior competição entre o $\mathrm{Na}$ e o K pelos sítios de absorção ou a um maior efluxo de $\mathrm{K}$ das raízes (MARschner, 1995). Redução na concentração de K, sob estresse salino, é um complicador adicional para o crescimento das plantas visto que, em algumas situações, esse elemento é o principal nutriente a contribuir para o decréscimo do potencial osmótico, uma estratégia necessária à absorção de água nessas circunstâncias (JESCHKE et al., 1986; MARSCHNER, 1995). Em relação ao cálcio, tem sido demonstrado que o aumento da salinidade pode induzir deficiência desse nutriente (LACERDA, 2000; Ho E AdAms, 1994). A redução na absorção de Ca pode levar à perda da integridade da membrana plasmática, com conseqüente perda da capacidade de absorção de alguns íons, principalmente o K (RENGEL, 1992; CACHORRO et al., 1994). Variedades tolerantes tendem a apresentar maiores taxas de transferência de $\mathrm{K}$ e apenas leve redução na transferência de Ca para a parte aérea, visando manter uma relação positiva entre esses nutrientes e os íons $\mathrm{Na}$ e Cl (Niv et al., 1995).

A Região Nordeste do Brasil é a maior produtora de maracujá-amarelo, com produção, em 2003, de 215.000 t (Iвge, 2005). No entanto, a produtividade dessa cultura é baixa, devido, principalmente, ao déficit hídrico que ocorre nos meses mais quentes do ano. Assim, o emprego de irrigações suplementares pode constituir-se em uma prática importante para o incremento da produtividade. Porém, a qualidade da água disponível para a irrigação pode não ser a mais adequada ao crescimento normal das plantas do maracujazeiro, em razão, principalmente, da presença de sais em quantidades relativamente elevadas.

Os resultados relacionando a resposta do maracujazeiro da espécie Passiflora edulis à salinidade têm sido divergentes, visto que AyERS E WeSTCOT (1991) 
classificaram essa espécie como sensível, enquanto os dados obtidos por SOAREs et al. (2002) indicam uma ligeira tolerância do maracujazeiro-amarelo (Passiflora edulis Sims f. flavicarpa Deg) a esse fator abiótico. Assim, o presente trabalho objetivou avaliar a influência da salinidade sobre o crescimento, absorção e distribuição de $\mathrm{Na}, \mathrm{Cl}$ e dos macronutrientes pelo Maracujazeiro-amarelo, uma das principais fruteiras da região Nordeste do Brasil.

\section{MATERIAL E MÉTODOS}

O trabalho foi desenvolvido em casa de vegetação da Embrapa Mandioca e Fruticultura, localizada em Cruz das Almas/BA. Para esse estudo usou-se sementes de Passiflora edulis Sims f. flavicarpa Deg (Maracujazeiro-amarelo). As sementes foram selecionadas e colocadas para germinar em vasos plásticos pretos e com capacidade para $2,2 \mathrm{dm}^{3}$. O substrato utilizado para o plantio foi composto de uma mistura de vermiculita expandida e turfa processada o qual foi lavado abundantemente com água de torneira, com as seguintes características químicas: condutividade elétrica $=0,282 \mathrm{dS} \mathrm{m}^{-1} ; \mathrm{pH}$ $=7,1 ; \mathrm{K}=0,17 \mathrm{cmol}_{\mathrm{C}} \mathrm{dm}^{-3} ; \mathrm{Ca}=0,2 \mathrm{cmol}_{\mathrm{C}} \mathrm{dm}^{-3} ; \mathrm{Mg}=$ $0,2 \mathrm{cmol}_{\mathrm{c}} \mathrm{dm}^{-3}$. Esse procedimento teve por objetivo a lixiviação dos nutrientes que, eventualmente, estivessem presentes. Realizou-se a semeadura empregando-se cinco sementes por vaso. O experimento foi instalado em delineamento inteiramente casualizado, com três tratamentos (concentrações de $\mathrm{NaCl}$ ) e 15 repetições, sendo cada planta considerada como uma parcela experimental.

Da semeadura até cinco dias após a emergência, as irrigações foram realizadas apenas com água de torneira. Após esse período, que durou 15 dias, foram descartadas as plântulas menos vigorosas, deixando-se uma por vaso. Em seguida ao desbaste, as plântulas passaram a ser fertilizadas com $800 \mathrm{~mL}$ de uma solução nutritiva de crescimento, contendo a seguinte composição, em m mol L-1: ${\mathrm{N}-\mathrm{NO}_{3}}^{-}$ $(5,0) ; \mathrm{P}(1,0) ; \mathrm{K}(4,0) ; \mathrm{Ca}(2,4) ; \mathrm{Mg}(1,0) ; \mathrm{S}(2,4) ; \mathrm{B}(0,023)$; $\mathrm{Cl}(0,009) ; \mathrm{Mn}(0,0046) ; \mathrm{Zn}(0,0004) ; \mathrm{Cu}(0,0002) ; \mathrm{Mo}$ $(0,0003)$ e $\mathrm{Fe}(0,005)$. Os tratamentos salinos também foram aplicados quinze dias após a semeadura, pela adição de $\mathrm{NaCl}$ à solução de crescimento, para a obtenção das concentrações finais de 0,50 e $100 \mathrm{~m}$ mol L-1 de $\mathrm{NaCl}$, que apresentaram, respectivamente, condutividades elétricas de 1,$1 ; 3,8$ e $6,5 \mathrm{dS} \mathrm{m}^{-1}$. Para se evitar a possibilidade de choque osmótico às plantas, a imposição do estresse salino foi de $50 \mathrm{~m}$ mol L ${ }^{-1}$ a cada 24 horas (LACERDA, 2000). O pH inicial das soluções nutritivas foi sempre ajustado para um valor entre 6,2 e 6,5. Como forma de repor a água perdida por evapotranspiração, as irrigações foram diárias e com água de torneira (MANIOS et al., 2003; SAlAun et al., 2005) que apresentava, como já mencionado, condutividade elétrica de $0,282 \mathrm{dS} \mathrm{m}^{-1}$.

A cada 15 dias, o substrato foi lavado abundantemente com água de torneira e depois com água destilada, para evitar sua salinização. Após esse procedimento, $800 \mathrm{~mL}$ da solução de crescimento, juntamente com o $\mathrm{NaCl}$, foram novamente colocados no substrato. No encerramento do experimento, que ocorreu 50 dias após o início da imposição do estresse, e quando as plântulas estavam com 65 dias após a semeadura, foram avaliados, inicialmente, a altura das plantas e o número de folhas. Após esses procedimentos, as plantas foram retiradas do substrato e divididas em raiz, caule + pecíolo, folhas com idades mais avançadas (FV, as seis folhas mais próximas da base do caule) e folhas recém-expandidas e em expansão (FN, todas as folhas restantes e que se localizavam mais próximas do ápice caulinar). Das 15 plantas que formavam as repetições dos tratamentos, tomou-se, ao acaso, três plantas de cada tratamento e determinou-se a área de todas as folhas, utilizando-se um integrador de área marca Delta T, mod. MK2. As diferentes partes das plantas foram colocadas para secar em estufa de circulação forçada de ar, a $75{ }^{\circ} \mathrm{C}$, por um período de 96 horas. Posteriormente, foram computados os dados de massa seca das folhas, caule + pecíolo e das raízes e, com esses dados, estimou-se a relação raiz:parte aérea. Com base na relação área foliar/massa seca das três plantas selecionadas, estimou-se a área foliar de todas as plantas dos respectivos tratamentos.

Para determinar a concentração de $\mathrm{Na}, \mathrm{Cl}, \mathrm{N}$, $\mathrm{P}, \mathrm{K}, \mathrm{Ca}, \mathrm{Mg}$ e $\mathrm{S}$, os caules + pecíolos, as folhas e as raízes de três plantas, das 15 plantas inicialmente utilizadas, foram combinados entre si, formando, ao final, cinco repetições. Nesse caso, a análise estatística foi realizada com base nas cinco repetições e levando em consideração o delineamento inteiramente casualizado. Posteriormente, essas partes combinadas foram moídas em moinho tipo Willy, com peneira de 20 mesh (malhas por polegada ${ }^{2}$ ). As análises químicas foram realizadas apenas nos tecidos vegetais dos tratamentos 0 e $100 \mathrm{~m} \mathrm{~mol} \mathrm{~L}^{-1}$ de $\mathrm{NaCl}$, seguindo os procedimentos analíticos descritos por MALAVOLTA et al. (1989). O conteúdo dos elementos nas plântulas foi calculado com base na concentração de cada elemento na massa seca.

Para efeito de comparação entre os tratamentos, calculou-se, para cada média, seu respectivo erro padrão (EPM). Para a análise das características de crescimento consideraram-se 15 repetições, enquanto para a análise química, apenas cinco. A sobreposição das barras do EPM indica não haver diferenças estatísticas entre os tratamentos (Astolfi et al., 2005; DA SiLva et al., 2006). 


\section{RESULTADOS E DISCUSSÃO}

No presente trabalho não se observou sintoma de toxidez por sódio $(\mathrm{Na})$ e cloro $(\mathrm{Cl})$, como por exemplo o aparecimento de clorose e queima das bordas das folhas mais velhas, mesmo quando se utilizou a concentração mais alta de $\mathrm{NaCl}$. Segundo SOARES et al. (2002), na fase inicial de crescimento do maracujazeiro, o efeito da salinidade pode ser mais prejudicial devido ao efeito físico (redução na quantidade de água disponível às plantas, por exemplo) e menos devido ao efeito tóxico direto do $\mathrm{Na}$ e Cl.

Os resultados verificados para as características de crescimento estão apresentados na Figura 1. Observa-se que a altura foi maior para as plantas cultivadas na ausência de $\mathrm{NaCl}$. Também, a massa seca total (MST) foi afetada pela disponibilidade de $\mathrm{NaCl}$ no meio de cultivo: para o controle (sem $\mathrm{NaCl}$ ) obteve-se um valor de 2,53 g de MST, enquanto para as concentrações de 50 e $100 \mathrm{~m}$ mol L ${ }^{-1}$, as produções foram, respectivamente, de 1,96 g e 1,94 g. A percentagem de redução provocada pela concentração de $100 \mathrm{~m} \mathrm{~mol} \mathrm{~L}^{-1}$, em relação ao controle, foi de apenas $23,3 \%$

A massa seca das raízes, folhas e caule, à semelhança da massa seca total, também apresentou redução em função das aplicações de $\mathrm{NaCl}$. Os decréscimos no acúmulo de matéria seca foram de $20,0 \%$ para as raízes, $22,0 \%$ para as folhas e $28,0 \%$ para o caule + pecíolo. Como conseqüência dessa semelhança na redução da massa seca dos componentes das plantas, não foi verificada influência da salinidade sobre a relação raiz:parte aérea. Esse fato significa que a imposição do estresse não determinou competição pela distribuição de assimilados entre a raiz e a parte aérea.

Quando cultivadas com $100 \mathrm{~m} \mathrm{~mol} \mathrm{~L}^{-1}$, as plantas apresentaram, em média, 10,3 folhas, enquanto para as plantas controle esse número foi de 11,5 , sendo essa um das características da planta menos afetadas pela salinidade (redução significativa, mas de apenas 10,5\%). A área foliar (AF) também foi reduzida (em torno de 18,9\%) pelo maior nível de salinidade. Esse menor valor de AF esteve mais relacionado ao tamanho médio de cada folha do que ao número de folhas, assemelhando-se aos resultados obtidos também com maracujazeiro, por SOARES et al. (2002). Para alguns autores, redução em AF é um importante mecanismo adaptativo de plantas cultivadas sob excesso de sais e estresse hídrico, visto que, sob tais condições, é interessante a redução na transpiração e, conseqüentemente, diminuição do carregamento de $\mathrm{Na}$ e $\mathrm{Cl}$ no xilema e conservação da água nos tecidos das plantas, segundo CRUz et al. (2003).

Nas plantas-controle, a concentração de $\mathrm{Na}$ foi igual para os órgãos estudados (Figura 2). No entanto, quando houve a adição de $\mathrm{NaCl}$ à solução, a concentração desse elemento aumentou em todos os órgãos da planta, sendo mais alta nas folhas mais velhas (FV) e, posteriormente, nas folhas mais novas. Aparentemente não foi verificada inibição do transporte do Na para a parte aérea, visto que suas maiores concentrações foram observadas nas folhas.

A concentração de $\mathrm{Cl}$ também aumentou em função do aumento do nível de salinidade no meio de crescimento (Figura 2). Contudo, a maior concentração desse elemento foi observada nas folhas mais velhas seguida das raízes.

A habilidade das plantas do maracujazeiro em manter os íons tóxicos compartimentalizados nas folhas mais velhas (no caso do $\mathrm{Na} \mathrm{e} \mathrm{Cl}$ ) ou nas raízes (no caso do $\mathrm{Cl}$ ) parece ser um mecanismo adaptativo importante, para proteção dos ápices foliares, possibilitando a manutenção de uma produção contínua de folhas (LACERDA et al., 2001). Como no presente trabalho o número de folhas foi um dos componentes de crescimento menos afetado pela salinidade, é possível sugerir que esse mecanismo funciona também nas plântulas do maracujazeiro. Ressalte-se que para o tratamento de $100 \mathrm{~m} \mathrm{~mol} \mathrm{~L}^{-1}$, nos tecidos da raiz, caule + pecíolo e folhas novas, ocorreram concentrações de $\mathrm{Cl}$ superiores aos de $\mathrm{Na}$.

Em função desse resultado observou-se que a absorção total de $\mathrm{Cl}$ foi quase o dobro do $\mathrm{Na}$ absorvido (Figura 3). Esses resultados são comumente observados e explicados pela característica de anion livre de cloro na planta, o que lhe confere maior mobilidade e transporte mais elevado do que o $\mathrm{Na}$ (FernANDes et al., 2002; MARsChNer, 1995).

$\mathrm{O}$ conteúdo total de $\mathrm{N}$ e Ca não foi afetado pela salinidade (Figura 3), discordando de MARSCHNER (1995), para quem a presença do íon $\mathrm{Cl}$ em solução pode reduzir a absorção de $\mathrm{N}$, principalmente quando fornecido na forma nítrica, efeito denominado antagonismo.

Quando se avaliam as concentrações do $\mathrm{N}$ e Ca nos diferentes órgãos da planta também observase que elas não foram influenciadas pela aplicação do estresse salino (Figura 4). Assim é possível sugerir que a manutenção das absorções de $\mathrm{N}$ e $\mathrm{Ca}$, bem como das concentrações desses elementos na planta, podem ter contribuído para minimizar o efeito da salinidade sobre as plântulas do maracujazeiro. 

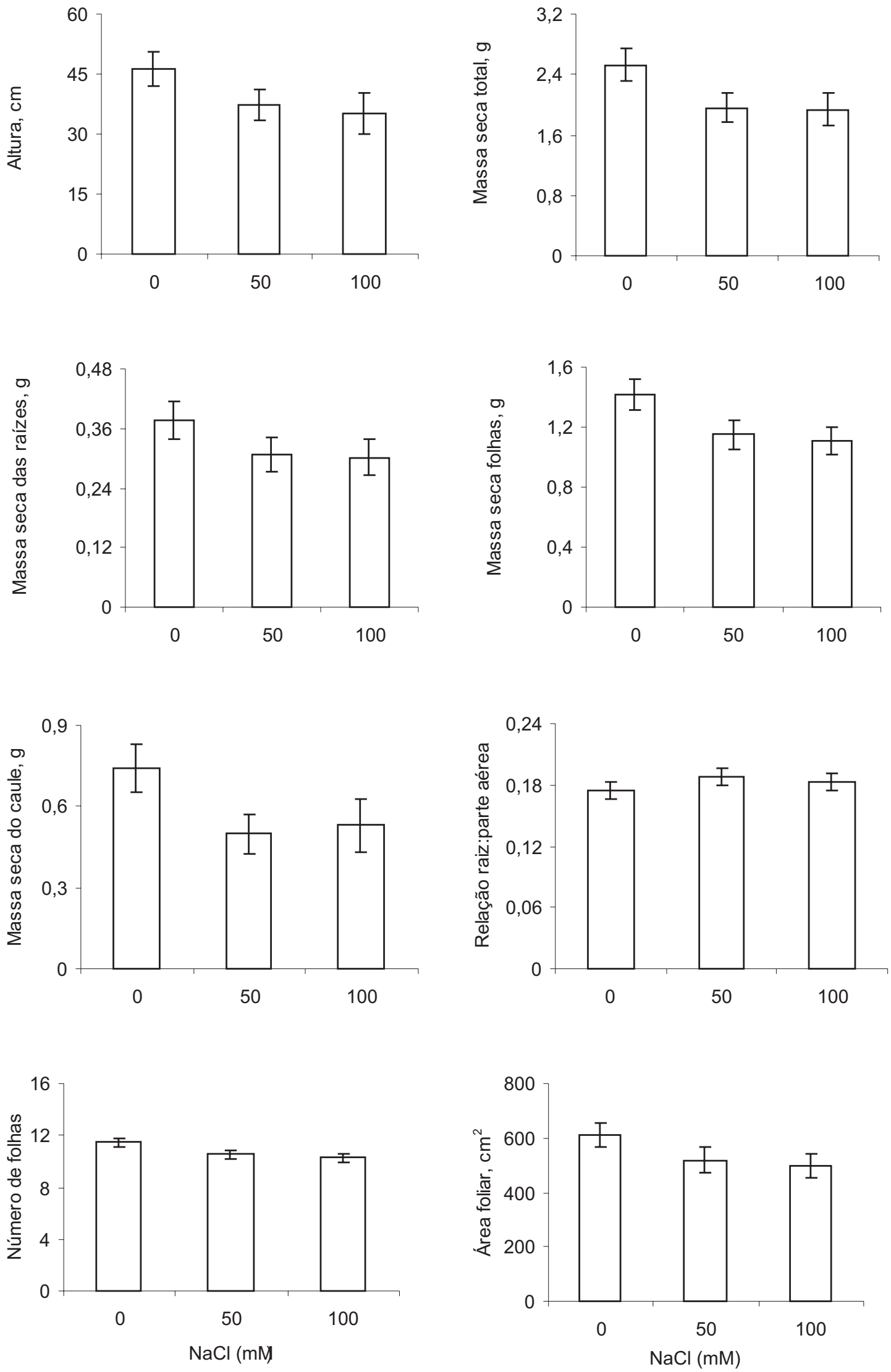

Figura 1. Influência da salinidade sobre as características de crescimento de plântulas de maracujazeiro-amarelo, cultivadas por 50 dias em substrato inerte acrescido de solução nutritiva. Barras representam o erro-padrão da média (n=15). 

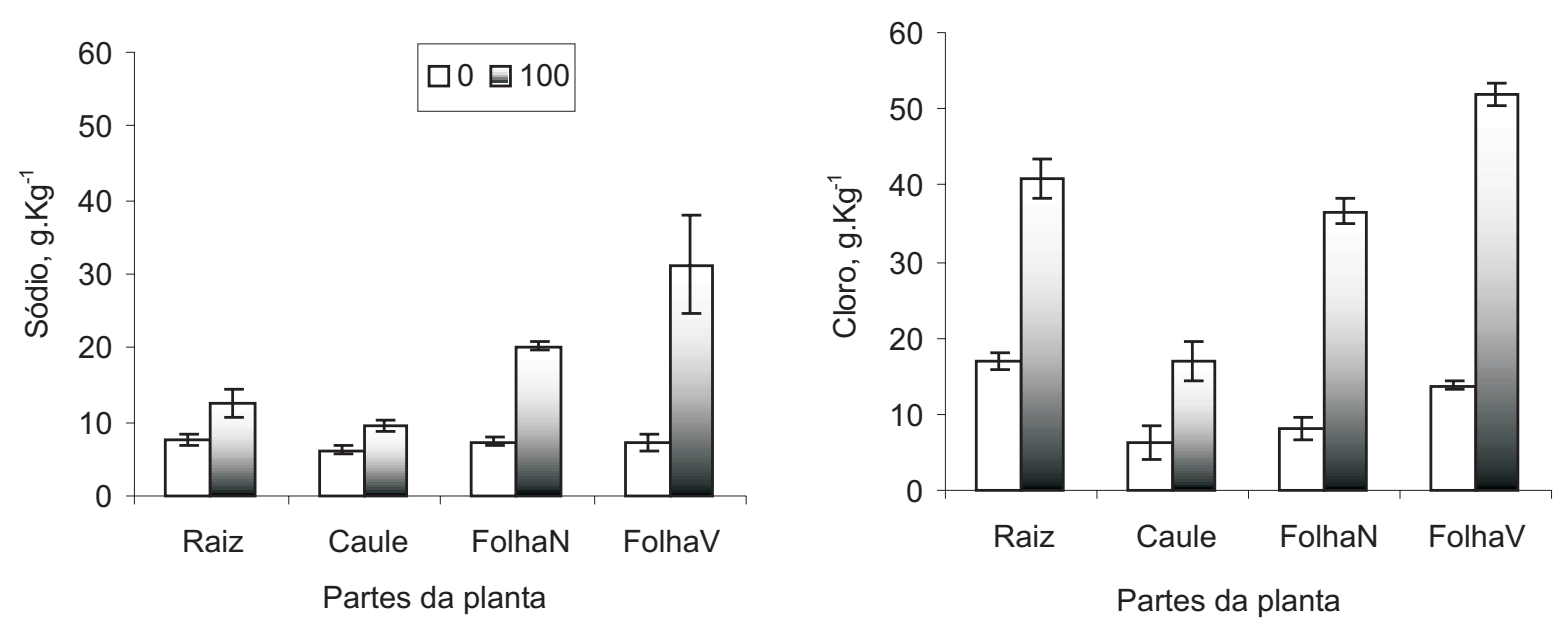

Figura 2. Efeito do tratamento salino sobre a concentração de sódio e cloro em diferentes partes das plântulas de maracujazeiro-amarelo, cultivadas por 50 dias em substrato inerte acrescido de solução nutritiva. $\mathrm{N}=$ nova e $\mathrm{V}=$ velha. Barras representam o erro-padrão da média $(n=5)$.

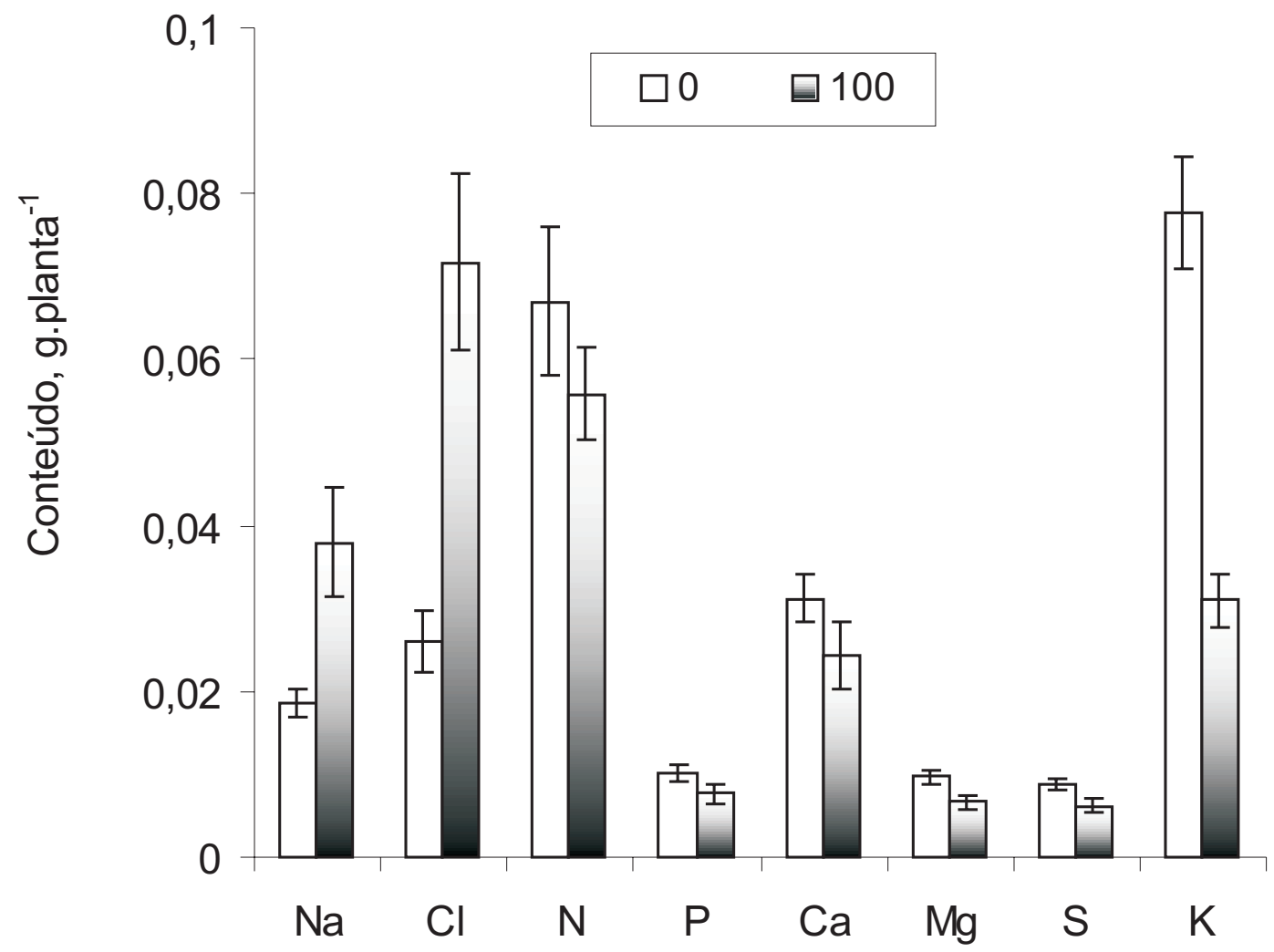

Figura 3. Efeito do tratamento salino sobre o conteúdo total de $\mathrm{Na}$ e $\mathrm{Cl}$ e dos macronutrientes das plântulas de maracujazeiro-amarelo, cultivadas por 50 dias em substrato inerte acrescido de solução nutritiva. Barras representam o erro-padrão da média $(n=5)$. 

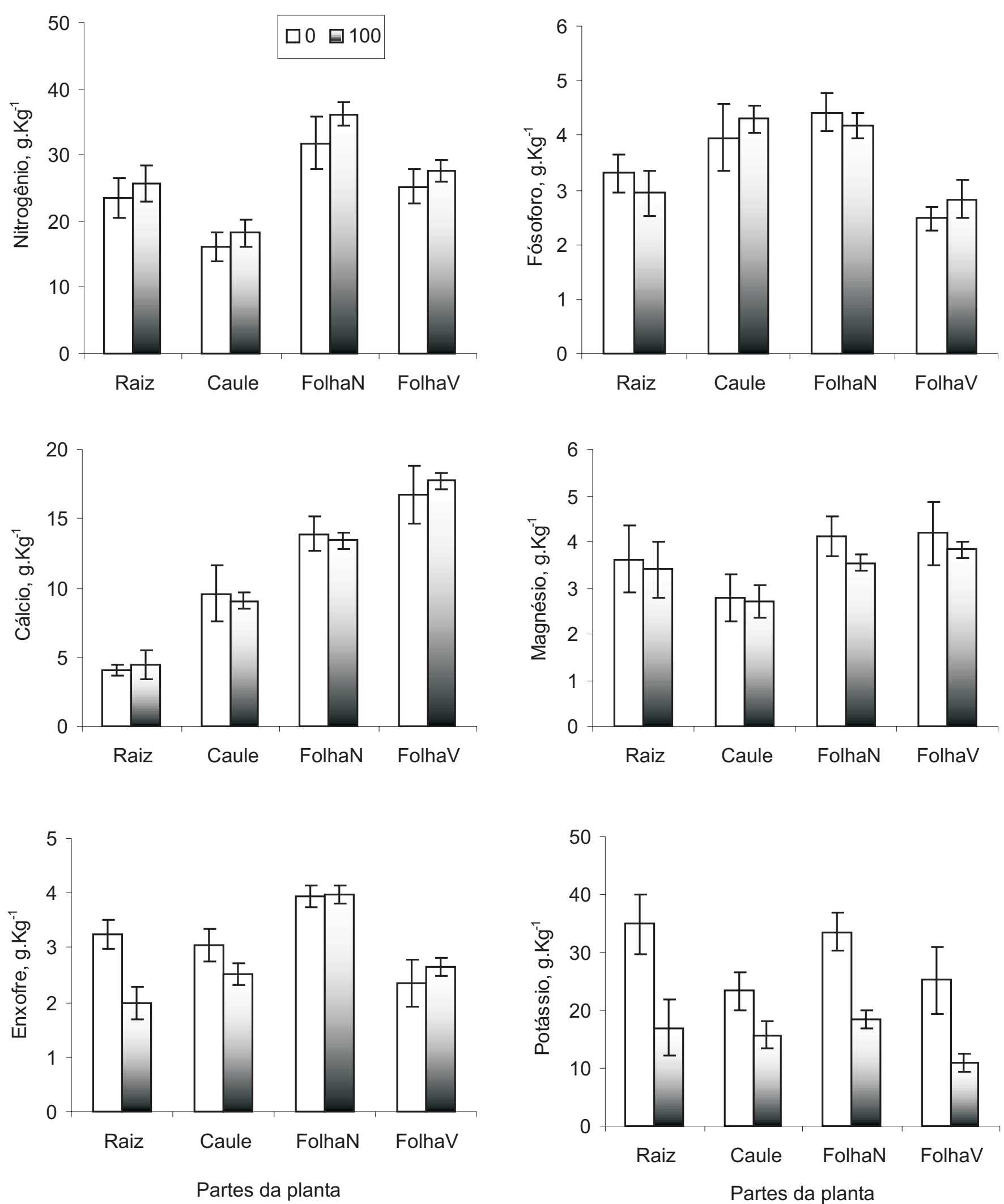

Figura 4. Efeito do tratamento salino sobre a concentração de nitrogênio, fósforo, cálcio, magnésio, enxofre e potássio das plântulas de maracujazeiro-amarelo, cultivadas por 50 dias em substrato inerte acrescido de solução nutritiva. Barras representam o erro-padrão da média $(n=5)$. 
As absorções totais de $\mathrm{P}$ e $\mathrm{Mg}$ foram significativamente maiores para as plantas crescidas sem estresse (Figura 3), indicando ter havido competição iônica entre o $\mathrm{Na}$ e o $\mathrm{Mg}$ e entre o $\mathrm{Cl}$ e o $\mathrm{P}$ conforme sugerido por Hu e SCHMidhalter (1997) e MARSCHNER (1995). No entanto, as concentrações de Mg e $\mathrm{P}$ nas diferentes partes das plantas, não foram influenciadas pela salinidade (Figura 4), indicando não ser o menor crescimento das plantas desse tratamento conseqüência da menor absorção desses nutrientes.

Apesar da menor absorção de enxofre (S) pelas plantas cultivadas sob salinidade (Figura 3), verificouse que para todas as folhas (folhas $\mathrm{N}$ e folhas $\mathrm{V}$ ) a concentração de $S$ não foi alterada pela imposição do estresse (Figura 4). No entanto, a concentração desse elemento foi pouco alterada no caule $(17,7 \%)$, porém, reduzida de forma efetiva nas raízes $(38,9 \%)$ sugerindo que para o maracujazeiro, a salinidade estimula o transporte do $\mathrm{S}$ das raízes para parte aérea e do caule para as folhas, o qual nessas circunstâncias, parecem ser um dreno mais efetivo para esse nutriente

Quando se avalia o conteúdo do K (Figura 3), verifica-se que sua absorção foi significativamente reduzida pela aplicação de $\mathrm{NaCl}$ no meio de crescimento. Tem sido sugerido que, sob salinidade, a menor absorção de Ca pode permitir que o Na seja incorporado à estrutura da membrana plasmática, reduzindo sua seletividade e, ou permitindo o efluxo de íons, notadamente o K (MARSCHNER, 1995). No entanto, como no presente trabalho a concentração de cálcio não foi alterada pela salinidade, é possível sugerir que a reduzida absorção de K esteja relacionada a uma competição direta que se estabelece entre o K e o Na pelos sítios de absorção na membrana plasmática das raízes. A concentração do K também foi reduzida pelo estresse salino em todos os órgãos avaliados (Figura 4); no entanto, foi observado que, nessas circunstâncias, a concentração desse elemento nas raízes, caule e folhas novas foram semelhantes, revelando claramente que a salinidade não alterou significativamente a distribuição do $K$ entre esses órgãos da planta. Dos macronutrientes essenciais, as concentrações de potássio foram as que tiveram as maiores reduções decorrentes da aplicação do estresse salino. Assim, é possível sugerir que a redução no crescimento das plantas cultivadas sob salinidade pode ter sido reflexo, pelo menos em parte, da menor concentração de $\mathrm{K}$ em seus tecidos, visto que esse elemento é de extrema importância para o ajustamento osmótico da planta, além de ser necessário para a manutenção da capacidade fotossintética, por sua importância na síntese de proteínas e ativação enzimática (TAIZ E ZeIger, 1998). Deficiência de K, induzida pelo aumento na concentração de $\mathrm{Na}$ no meio de crescimento também tem sido relacionada à redução do rendimento em diversas culturas, tais como tomate (SONG E FujIYAMA, 1996), e milho (Botella et al., 1997).

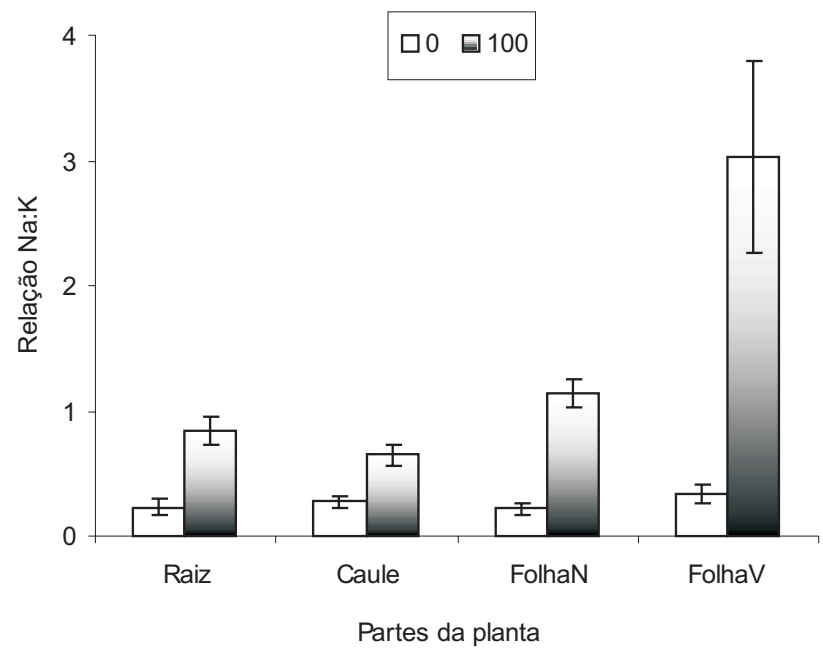

Figura 5. Efeito do tratamento salino sobre a relação $\mathrm{Na} /$ $\mathrm{K}$ em diferentes partes das plântulas de maracujazeiroamarelo, cultivadas por 50 dias em substrato inerte acrescido de solução nutritiva. $\mathrm{N}=$ nova e $\mathrm{V}=$ velha Barras representam o erro-padrão da média $(n=5)$.

A manutenção das concentrações de $\mathrm{Ca}, \mathrm{Mg}$, $\mathrm{P}$ e $\mathrm{N}$ e a redução de $\mathrm{K}$ em todos os órgãos das plântulas cultivadas sob estresse salino, parecem mostrar que se ocorrer ajustamento osmótico do maracujazeiro não é pelo maior acúmulo desses íons no vacúolo das células.

A possibilidade de que o Na possa ter substituído o K em sua função osmótica (WYN JONES, 1981; JESCHKE et al., 1986 e RAMOs et al., 2004) parece improvável, na medida em que o aumento da absorção de Na sob salinidade (de 0,019 para $0,038 \mathrm{~g}$ ) foi muito menor do que a absorção de K das plantas-controle $(0,078)$.

Como conseqüência da maior absorção e translocação de $\mathrm{Na}$ pelas plantas cultivadas sob salinidade, a relação desse íon com o $\mathrm{K}$ foi signficativamente aumentada (Figura 5). Verificou-se que a relação $\mathrm{Na}: \mathrm{K}$ foi mais alta para as folhas mais velhas, refletindo a capacidade das plântulas de maracujazeiro em aumentar o seqüestro de $\mathrm{Na}$ nessas partes da planta, ao mesmo tempo em que sua concentração de $\mathrm{K}$ se reduziu, como anteriormente comentado. É possível observar que, sob salinidade, a concentração de $\mathrm{K}$, mesmo tendo sido reduzida, ainda foi maior do que a de Na para as raízes e caule (relações $\mathrm{Na}: \mathrm{K}$ menores que 1) e ligeiramente semelhante para as folhas mais novas (relação Na:K igual a 1,1). Como conseqüência, observou-se uma 
relação Na:K mais favorável para as folhas mais novas e raízes, sítios metabolicamente mais ativos do que as folhas mais velhas, com maior relação. A manutenção de baixas relações $\mathrm{Na}: \mathrm{K}$, como verificada no presente trabalho, tem sido considerada como uma característica adaptativa das plantas para a manutenção do crescimento em ambientes salinos, pois permite que as células realizem suas principais funções em níveis próximos ao da normalidade das plantas (Grattan e Grieve, 1999).

Apesar das altas concentrações de $\mathrm{Na}$ e $\mathrm{Cl}$ nas plantas cultivadas sob o mais alto nível de salinidade, principalmente nas folhas, foi observado que a redução nos parâmetros de crescimento não foi tão expressiva. Assim, existe a possibilidade de que plântulas de maracujazeiro não dificultem a absorção dos íons $\mathrm{Na}$ e $\mathrm{Cl}$, mas tenham a capacidade de confiná-los em compartimentos com menor atividade metabólica, como raízes e folhas mais velhas, resultando como conseqüência, capacidade para minimizar a redução dos parâmetros de crescimento.

\section{CONCLUSÕES}

1. O crescimento das plântulas de maracujazeiro foi significativamente afetado pelos níveis de salinidade; no entanto, em função da pequena redução nos parâmetros de crescimento, é possível sugerir que, no presente trabalho, essas plântulas tenham apresentado moderada tolerância à salinidade.

2. A moderada tolerância esteve relacionada à manutenção das concentrações de N, P, Ca e Mg nos tecidos das plantas, à capacidade de confinar os íons $\mathrm{Cl}$ nas raízes e $\mathrm{Na}$ nas folhas mais velhas e a manutenção de uma relação baixa entre $\mathrm{Na}$ e K nas raízes e folhas mais novas.

\section{REFERÊNCIAS}

ASTOLFI, S.; ZUCHI, S.; PASSERA, C. Effect of cadmiun on $\mathrm{H}^{+}$ATPase activity of plasma membrane vesicles isolated from roots of different S-suplied maize (Zea mays L.) plants. Plant Science, Limerik, v.169, n.2, p.361-368, 2005.

AYERS, R.S.; WESTCOT, D.W. A qualidade da água na agricultura. Campina Grande: UFPB, 1991.218p. (Estudos FAO. Irrigação e Drenagem, 29)

BETHKE, P.C.; DREW, M.C. Stomatal and non-stomatal components to inhibition of photosynthesis in leaves of Capsicum annuum during progressive exposure to $\mathrm{NaCl}$ salinity. Plant Physiology, Rockville, v.99, n.1, p.219-226, 1992.
BOTELLA, M. A.; MARTINEZ V.; NIEVESM.; CERDA, A. Effects of salinity on the growth and nitrogen uptake by wheat seedlings. Journal of Plant Nutrition, New York, v.20, n.6, p.793-804, 1997.

CACHORRO, P.; OTIZ, A.; CERDÁ, A. Implications of calcium nutrition on the response of Phaseolus vulgaris L. to salinity. Plant and Soil, Dordrecht, v.159, n.2, p.205-212, Jan. 1994.

CARNEIRO, P.T.; FERNANDES, P.D.; GHEYI, H.R.; SOARES, F.A.L. Germination and initial growth of precocious dwarf cashew genotypes under saline conditions. Revista Brasileira de Engenharia Agrícola, Campina Grande, v.6, n.2, p.199-206, 2002.

CRUZ, J.L.; PELACANI, C.R.; SOARES FILHO, W. dos S.; CASTRO NETO, M.T.; COELHO, E.F.; DIAS, A.T.; PAES, R.A. Produção e partição de matéria seca e abertura estomática do limoeiro 'Cravo' submetido a estresse salino. Revista Brasileira de Fruticultura, Jaboticabal, v.25, n.3, p.528-531, 2003.

DA SILVA, A.L.S.; SPERLING, P.; HORST, W.; FRANKE, S.; OTT, C.; BECKER, D.; STAB, A.; LORZ, H.; HEINZ, E. A possible role of sphingolipids in the aluminium resistance of yeast and maize. Journal of Plant Physiology, Leitzit, v.163, n.1, p.26-38, 2006.

FERREIRA, R.G., TÁVORA, F.J.A.F.; FERREYRAHERNANDEZ, F.F. Distribuição da matéria seca e composição química das raízes, caule e folhas de goiabeira submetida a estresse salino. Pesquisa Agropecuária Brasileira, Brasília, v.36, n.1, p.79-88, 2001

FERNANDES, A.R.; CARVALHO, J.G. de; CURI, N.; PINTO, J E.B.P.; GUIMARÃES, P de T. G. Nutrição mineral de mudas de pupunheira sob diferentes níveis de salinidade. Pesquisa Agropecuária Brasileira, Brasília, v.37, n.11, p.1613-1619, 2002.

GRATTAN, S.R.; GRIEVE, C.M. Salinity-mineral nutrient relations in horticultural crops. Scientia Horticulturae, Amsterdam, v.78, n.1, p.127-157, 1999.

HO, L.C.; ADAMS, P. Regulation of the partitioning of dry mater and calcium in cucumber in relation to fruit growth and salinity. Annal of Botany, London, v.73, n.5, p.539-545, 1994.

HOPKINS, G.W. Introduction to plant physiology, New York: John Wiley \& Sons, 1999. 512 p.

HU, Y.; SCHMIDHALTER, U. Interactive effects of salinity and macronutrient level on wheat - part II: composition. Journal of Plant Nutrition, New York, v.20, n.9, p.1169-1182, 1997.

IBGE. Disponível em: http://www.sidra.ibge.gov.br/bda/ tabela/protabl.asp? $\mathrm{z}=\mathrm{t} \& \mathrm{o}=11 \& \mathrm{i}=\mathrm{P}$ Acesso em: 15 agosto 2005 .

JESCHKE, W.D., ASLAM, Z., GREENWAY, H. Effects of $\mathrm{NaCl}$ on ion relations and carbohydrate status of roots and on osmotic regulation of roots and shoots of Atriplex amnicola. Plant Cell and Environment, Oxford, v.9, n.7, p.559-569, 1986.

LACERDA, C.F. Crescimento e acúmulo de solutos orgânicos e inorgânicos em dois genótipos de sorgo forrageiros submetidos a estresse salino. 2000. 163 f. Tese (Doutorado em Fisiologia Vegetal) - Universidade Federal de Viçosa, Viçosa, 2000. 
LACERDA, C.F.; CAMBRAIA, J.; CANO, M.A. O.; RUIZ.H.A. Plant growth and solute accumulation and distribution in two sorghum genotypes, under $\mathrm{NaCl}$ stress. Revista Brasileira de Fisiologia Vegetal, Lavras, v.13, n.3, p. 270-284, 2001.

MALAVOLTA, E.; VITTI, G.C.; OLIVEIRA, S.A. de Avaliação do estado nutricional das plantas: princípios e aplicações. Piracicaba: Potafós, 1989. 201p.

MANIOS, T.; STENTIFORD, E.I.; MILLNER, P.A. The effect of heavy metals accumulation on the chlorophyll concentration of Typha latifolia plantas, growing in a substrate containing sewage sludge compost and watered with metaliferus water. Ecological Engineering, Wolhusen, v.20, n.1, p.65-74, 2003.

MANSOUR, M.M.F.; SALAMA, K.H.A.; Al-MUTANA, M.M. Transport protein and salt tolerance in plants. Plant Science, Limerik, v.146, n.6, p.891-900, 2003.

MARSCHNER, H. Mineral nutrition of higher plants. 2.ed. San Diego: Academic Press, 1995. 889p.

NIU, X.; BRESSAN, R.A.; HASEGAWA, P.M.; PARDO, J.M. Ion homeostasis in $\mathrm{NaCl}$ stress environment. Plant Physiology, Rockville, v.109, n.3, p.735-742, 1995.

RAMOS, J.; LOPEZ, M.J.; BENLLOCH, M. Effects of $\mathrm{NaCl}$ and $\mathrm{KCl}$ salts on the growth and solute accumulation of the halophyte Atriplex nummularia. Plant and Soil, Dordrecht, v. 259, n. 1-2, p.163-168, 2004.

RENGEL, Z. Role of calcium in salt toxicity. Plant Cell and Environment, Oxford, v.15, n.6, p.625-632, 1992.
SALAUN, M.; GUÉRIN, V.; HUCHÉ-THÉLIER, L.; CHARPENTIER, S.; Le DILY, F. Nitrogen storage and mobilisation for spring growth in Ligustrum cultivated in container. Scientia Horticulturae, Amsterdam, v.103, n.4, p.461$471,2005$.

SHANNON, M.C.; GRIEVE, C.M. Tolerance of vegetable crops to salinity. Scientia Horticulturae, Amsterdam, v.78, n.1-4, p.538, 1998.

SOARES, F.A.L.; GHEYI, H.R.; VIANA; S.B.A.; UYEDA, C.A.; FERNANDES, P.D. Water salinity and initial development of yellow passion fruit. Scientia Agrícola, Piracicaba, v.59, n.3, p. 491-497, 2002.

SONG J.Q.; FUJIYAMA H. Importance of Na content and water status for growth in Na-salinized rice and tomato plants. Soil Science and Plant Nutrition, Tokyo, v.44, n.2, p.197-208, jun 1998.

TAIZ, L.; ZEIGER E. Plant Physiology. Massachusetts: Sinauer, 1998. 792p.

WYN JONES, R.J. Salt tolerance. In: JOHNSON, C.B. (Ed.). London: Physiological Processes Limiting Plant Productivity, 1981. p.271-292.

YAHYA, A. Salinity effects on growth and on uptake and distribution of sodium and some essential mineral nutrients in sesame. Journal of Plant Nutrition, New York, v.21, n.7, p. 1439-1451, 1998. 